\title{
Analysis of Factors That Influence Consumers on the Purchasing Power of "GW" Bags in Probolinggo
}

\author{
Nuzulul Fatimah $^{1 *} \quad$ Emmywati $^{1} \quad$ Dewi Kartikaningsih ${ }^{2}$ \\ 1.School of Economics, STIE Mahardhika, Jalan Wisata Menanggal No.42 A Surabaya, Indonesia \\ 2.School of Management, Labora School of Management, Taman Modern Palem Raja Street Blok \\ B7 No. 7-8 Cakung Jakarta Timur Indonesia
}

\begin{abstract}
The world of fashion is a world that never dies, fashion always changes and has its own trend. This phenomenon can be seen in various fashion shopping centers that are never empty of visitors. Competition in the fashion world is fairly tight, demanding fashion producers/sellers, especially in the field of bags, to be able to sell products that attract buyers. Bag itself is one of the needs that are needed to carry out daily activities, both in education and in the world of work. We can see that bags can be used at various ages, so you can say that the need for bag use has no limits. This research was conducted to find out what are the factors that can affect the level of consumer purchasing power and the dominant factors affecting the purchasing power of consumers of GW bags in Probolinggo. The population in this study is GW bag consumers in Probolinggo with a sample of 50 respondents and data obtained directly from respondents by means of observation, interviews and questionnaires. The analysis used in this study is Factor Analysis with 9 variables and the dominant variable is the level of income.In this study using a quantitative method and using the SPSS version 16.00 application and obtained results that show the dominant variables as follows, level of income 5.567, level of education 1.085, level of need 0.763 , socio-cultural 0.619 , price 0.369 , mode / design 0.249 , lifestyle 0.178 , buying interest 0.092 , consumer environment 0.077 . From the value that has been explained there is the highest value is the level of income, then the level of income is the most dominant variable in influencing the $\mathrm{Y}$ variable and from the results of the calculation of SPSS version 16.00 there are 2 group factors in this study.
\end{abstract}

Keywords: Analysis factors, purchasing power, level of income

DOI: $10.7176 / \mathrm{JMCR} / 53-05$

\section{Introduction}

The world of fashion is a world that never dies, fashion always changes and has its own trend. This phenomenon can be seen in various fashion shopping centers that are never empty of visitors. Competition in the fashion world is fairly tight, demanding manufacturers / fashion buyers, especially in the field of bags to be able to sell products that attract buyers.

In the business economic environment, it is better to pay attention to a number of things related to the community at large, one of which is about the purchasing power of the community where the people's purchasing power can be used as a consideration in making business decisions and strategies.

This people's purchasing power is characterized by an increase or decrease in demand for goods or services from consumers, where purchasing power increases if it is higher than the previous period while declining purchasing power is characterized by a higher ability of purchasing power than in the previous period.

The marketing person himself must function as an observer of all the factors that affect the purchasing power of his customers, and must also be able to understand the nature of the system in which he is located, opportunities, and limitations that can influence.

The purpose of this study was to analyze the factors that influence the purchasing power of consumers of GW bags in Probolinggo and to analyze the dominant factors affecting the purchasing power of consumers of GW bags in Probolinggo.

\section{REVIEW OF RELATED STUDY \\ Theoritical basis \\ Definition of Marketing Management}

Ernie and Kurniawan (2013) explain the definition of Marketing Management is a management activity based on its function which essentially strives to identify what is actually needed by consumers, and how it can be fulfilled. To be able to identify what consumers need, a business man need to do marketing research, including a survey of consumer purchasing power, about what consumers really want.

\section{Purchasing Power}

According to Dr. Supawi Pawenang (2016) purchasing power is the ability of people to spend their money in the form of goods and services, the lower value of a society's purchasing power is closely related to the deteriorating economic condition, which means that the ability of people to buy goods or services is lower. 
From this definition, it can be explained that purchasing power is related to the level of need, price, and income. Consumers with low purchasing power or relatively low income, will consume products at relatively cheap prices with relatively fewer amounts in order to meet their needs, and if possible can meet all their needs.

\section{Factors that Influence Purchasing Power}

The following can be illustrated the conceptual framework used as the rationale in this study. The framework is the rationale for carrying out the analysis in this study.

\begin{tabular}{|c|c|c|}
\hline Variable & Sub Variable & \\
\hline Level of Income (X1) & $\begin{array}{l}\text { 1. Salary }(\mathrm{x} 1.1) \\
\text { Own business income }(\mathrm{x} 1.2) \\
\text { 3. Other business income }(\mathrm{x} 1.3)\end{array}$ & \\
\hline $\begin{array}{l}\text { Level of education } \\
\qquad \text { (X2) }\end{array}$ & $\begin{array}{l}\text { 1.Formal } \\
\text { 2. Informal }(\mathrm{x} 2.2) \\
\text { 3. Access and equity }(\mathrm{X} 2.3)\end{array}$ & \\
\hline $\begin{array}{l}\text { Level of need } \\
\qquad \text { (X3) }\end{array}$ & $\begin{array}{l}\text { 1. Social need }(\times 3.1) \\
\text { 2. Civilization }(\times 3.2) \\
\text { 3.Aage }(\times 3.3)\end{array}$ & \\
\hline $\begin{array}{l}\text { Socio-cultural } \\
\text { (X4) }\end{array}$ & $\begin{array}{l}\text { 1. Clothing and appearance }(x 4.1) \\
\text { 2. Public relations }(x 4.2) \\
\text { 3. Value and norm }(x 4.3)\end{array}$ & Factor Analysis \\
\hline Price (X5) & $\begin{array}{l}\text { 1.High Price } \quad(x 5.1) \\
\text { 2. Low Price }(x 5.2) \\
\text { 3. Price Competitiveness }(x 5.3)\end{array}$ & \\
\hline Design (X6) & $\begin{array}{l}\text { 1.Standart of product (x6.1) } \\
\text { 2. Specific of Product }(\times 6.2) \\
\text { 3. Quality of goods }(\times 6.3)\end{array}$ & $\begin{array}{l}\text { Dominant Factors } \\
\text { in Purchasing }\end{array}$ \\
\hline Lifestyle (X7) & $\begin{array}{l}\text { 1.Activities } \\
\text { 2. Opinion }(x 7.2) \\
\text { 3. Consumer Interest }(X 7.3)\end{array}$ & Power (Y) \\
\hline $\begin{array}{l}\text { Interest in Buying } \\
\text { (X8) }\end{array}$ & $\begin{array}{ll}\text { 1.Transactional } & (\mathrm{x} 8.1) \\
\text { 2.Prefrential } & (\mathrm{x} 8.2) \\
\text { 3. Explorative }(\mathrm{x} 8.3) & \end{array}$ & \\
\hline $\begin{array}{l}\text { Consumer environment } \\
\text { (X9) }\end{array}$ & $\begin{array}{l}\text { 1. Social stimulation (x9.1) } \\
\text { 2. Reference group (x9.2) } \\
\text { 3. Family (x9.3) }\end{array}$ & \\
\hline
\end{tabular}

\section{Hypothesis}

The hypothesis is a presumption or assumption that must be tested through data or facts obtained by means of research (Dantes, 2012). Based on the background, formulation of the problem, and the foundation of the theory, and the conceptual framework, the hypothesis of this study are as follows:

Factors that influence purchasing power are:

Income level (x1)

Requirement level (x2)

Price (x5)

Lifestyle (x7)

The dominant factor affecting the purchasing power of consumers of GW bags in Probolinggo is the level of income $(\mathrm{X} 1)$.

\section{RESEARCH METHOD}

\section{Types of Research}

According to Borg and Gall in Sugiyono (2015) there are 2 types of research methods namely quantitative and qualitative methods, quantitative methods are also called discovery methods, because this method can be found and developed by various new science and technology. And this method data uses research data in the form of 
numbers and analysis using statistics.

Based on the description stated above, it can be concluded that this study uses a quantitative approach because all data obtained are in the form of numbers and analyzed using statistical analysis techniques. This research is a type of survey research, where information is collected from respondents using questionnaires or questionnaires.

\section{Population and Sample}

According to Sugiyono (2015) population is a region of generalization consisting of objects / subjects that have certain qualities and characteristics set by researchers to be studied and then conclusions drawn. In this study the population was GW bag consumers in Probolinggo.

According to Sugiyono (2015) Samples are part of the number of characteristics possessed by the population. If the population is large, and researchers are not likely to learn all that exists in the population, for example due to limited funds, energy and time, the researcher can use samples taken from that population.

An important sampling technique is used in a study because it is a sampling technique to determine the sample to be used in a study. In this study the authors used probability sampling techniques with a type of simple random sampling.

According to Sugiyono (2014) Probability sampling is a sampling technique that provides equal opportunities for each element (member) of the population to be selected as a sample. While the type of simple random sampling is the taking of sample members from the population carried out randomly regardless of the strata that exist in the population. This method is done because members of the existing population have the same opportunity to be chosen as samples.

From this explanation, Roscoe in Sugiono (2012) suggests that the sample size for research is a feasible size in the study, between 30 - 500. And in this study 50 samples will be taken to study. Because to reduce generalizations when doing research.

\section{ANALYSIS OF RESEARCH RESULTS AND DISCUSSION \\ Research Result \\ Factor Analysis}

According to Usman (2013) Factor Analysis is part of multivariate which is useful for reducing variables. The way it works is to collect variables that correlate into one or several factors, where between one factor and another factor are independent or uncorrelated. From these formed factors, later it will be able to see the factors that become the main (dominant) explanation of a population.

Table 4.37

\section{KMO and Bartlett's Test}

\begin{tabular}{|ll|r|}
\hline $\begin{array}{l}\text { Kaiser-Meyer-Olkin Measure of Samp } \\
\text { Adequacy. }\end{array}$ &, 847 \\
& & \\
Bartlett's Test of & Approx. Chi-Squar & 361,853 \\
Sphericity & df & 36 \\
& Sig. &, 000 \\
\hline
\end{tabular}

Source : From data processing researcher (2017)

In this study the KMO value test requirements are greater than 0.5. The KMO Test results can be found in table 4.37 and the value of 0.847 is obtained, which means that the value of the value is greater than the specified value of 0.5 so that it can be declared to pass the KMO test because it has met the requirements and proceed to the Barlett Test.

Table 4.37 shows the sig value of 0,000 and this value is smaller than $0.05 / 5 \%$ (in this study using a significant level of 5\%). So this research can be declared passed from the barlet test because the test meets the requirements for further testing.

After being passed from the KMO Test and Barlet Test followed by the MSA Test (Measure of Sampling Adequacy) which is useful for measuring how precisely a variable is predicted by another variable with a relatively small error. as the MSA (Measure of Sampling Adequacy) criteria, then attributes that have MSA $>0.5$ are valid attributes. Whereas if an attribute has an MSA value of $<0.5$, then the attribute is invalid, and must be issued or not need to be used to measure the variable.

Furthermore, in table 4.38, it can be seen that the value of Anti-image correlation from table 4.38 which is marked (a) is the value of Anti-image correlation level of 0.890 , the value of Anti-image correlation level of 0.862, the value of Anti-image correlation level needs 0.718, the value of Anti -image Correlation of socio- 
culture 0.852 , Anti-image Correlation value is 0.883 , Anti-image Correlation mode / design value is 0.826 , Antiimage Correlation lifestyle value is 0.887, Anti-image Correlation value buying interest is 0.778, Anti-image Correlation value is consumer environment 0.817. Based on the data in table 4.40, this study can be declared passed from the MSA test because all values above $>0.05$ and the test is declared to be eligible.

Table 4.38

Anti-Image Matrices

\begin{tabular}{|c|c|c|c|c|c|c|c|c|c|}
\hline & $\begin{array}{l}\text { INCOME } \\
\text { LEVEL }\end{array}$ & $\begin{array}{l}\text { EDUCATION } \\
\text { LEVEL }\end{array}$ & $\begin{array}{l}\text { NEED } \\
\text { LEVEL }\end{array}$ & $\begin{array}{c}\text { SOCIO-CUL } \\
\text { TURAL }\end{array}$ & PRICE & DESIGN & LIFESTYLE & $\begin{array}{c}\text { INTEREST } \\
\text { IN } \\
\text { BUYING } \\
\end{array}$ & $\begin{array}{c}\text { CONSUMER } \\
\text { ENVIRONT } \\
\text { MENT } \\
\end{array}$ \\
\hline Anti-image Co & & & & & & & & & \\
\hline $\begin{array}{l}\text { INCOME LEVEL } \\
\text { EDUCATION }\end{array}$ & 265 &,,- 068 & 017 & ,032 & ,015 &,- 104 &,- 003 &,- 030 &, 022 \\
\hline LEVEL &,- 068 &, 356 &,- 003 &,- 165 &,- 020 &, 030 &,- 085 &, 061 &,- 066 \\
\hline $\begin{array}{l}\text { NEED LEVEL } \\
\text { SOCIO-CULTUR }\end{array}$ &,- 017 &,- 003 & 856 &,- 172 &, 049 &,- 025 &,- 022 &,- 054 &, 065 \\
\hline $\begin{array}{l}\text { AL } \\
\text { PRICE }\end{array}$ & ,032 &,- 165 &,- 172 &, 667 &,- 018 &,- 034 &, 037 &,- 025 &, 025 \\
\hline DESIGN &, 015 &,- 030 & ,049 &,- 018 & , 150 &,- 086 &,- 045 &,- 007 &,- 004 \\
\hline $\begin{array}{l}\text { LIFESTYLE } \\
\text { INTEREST IN }\end{array}$ &,- 104 &, 030 &,- 025 &, 034 &,- 186 &, 138 &,- 019 &, 026 &,- 021 \\
\hline BUYING &,- 003 &,- 085 &,- 022 &,- 037 &,- 145 &,- 019 &, 161 &,- 076 &, 021 \\
\hline CONSUMER &,- 030 &, 061 &,- 064 &,- 025 &,- 007 &, 026 &,- 076 &, 161 & -135 \\
\hline ENVIRONTMENT & 022 &,- 066 &, 065 &, 025 &,- 004 &,- 021 &, 021 & -136 &, 215 \\
\hline Anti-image Co & & & & & & & & & \\
\hline $\begin{array}{l}\text { INCOME LEVEL } \\
\text { EDUCATION }\end{array}$ & 890 & -221 &,- 035 &, 076 & ,073 &,- 541 &,- 016 &,- 144 &, 091 \\
\hline LEVEL & -221 &, 862 &,- 006 &,- 338 &,- 129 &, 136 &,- 355 &, 256 &,- 240 \\
\hline $\begin{array}{l}\text { NEED LEVEL } \\
\text { SOCIO-CULTUR }\end{array}$ &,- 035 &,- 006 &, 718 &,- 228 &, 138 &,- 074 &,- 061 &,- 145 &, 151 \\
\hline $\begin{array}{l}\text { AL } \\
\text { PRICE }\end{array}$ &, 076 &,- 338 &,- 228 & 852 &,- 057 &,- 111 &, 114 &,- 077 &, 067 \\
\hline DESIGN &, 073 &,- 129 &, 138 &,- 057 & 883 &,- 594 & -292 &,- 047 &,- 022 \\
\hline $\begin{array}{l}\text { LIFESTYLE } \\
\text { INTEREST IN }\end{array}$ &,- 541 & ,136 &,- 074 &,- 111 &,- 594 & 826 &,- 128 &, 174 &,- 122 \\
\hline BUYING &,- 016 &,- 335 &,- 061 &, 114 &,- 292 &,- 128 &, 887 &,- 471 &, 111 \\
\hline CONSUMER &,- 144 &, 256 &,- 145 &,- 077 &,- 047 &,- 471 &,- 471 &, 776 &,- 723 \\
\hline ENVIRONTMENT &, 091 &,- 240 & ,151 &, 067 &,- 022 &,- 111 & ,111 &,- 723 & 817 \\
\hline
\end{tabular}

Source : From data processing researcher (2017)

Table 4.39

\begin{tabular}{|l|l|l|}
\hline \multicolumn{2}{|c|}{ Communalities } \\
\hline INCOME LEVEL & Initial & Exaction \\
EDUCATION LEVEL & 1,000 &, 717 \\
NEED LEVEL & 1,000 &, 651 \\
SOCIO-CULTURAL & 1,000 &, 731 \\
PRICE & 1,000 &, 591 \\
DESIGN & 1,000 &, 838 \\
LIFESTYLE & 1,000 &, 799 \\
INTEREST IN BUYING & 1,000 &, 859 \\
CONSUMER ENVIRONTMENT & 1,000 &, 730 \\
\hline
\end{tabular}

Source : From data processing researcher (2017)

Can be seen from table 4.39, explaining the level of income that has an extraction value of $0.717 \%$ variant that affects 1 factor, education level which has an extraction value of 0.661 variants that affects 1 factor, level of need which has an extraction value of 0.731 variants that affect 1 factor, social Culture which has an extraction value of 0.591 variants that affect 1 factor, Price which has an extraction value of 0.838 variants that affects 1 factor, Mode / Design which has an extraction value of 0.799 variants that affect 1 factor, Lifestyle which has an extraction value of 0.859 variants that affect 1 factor, Purchase Interest which has an extraction value of 0.730 variants that affects 1 factor, the Consumer Environment which has an extraction value of 0.725 variants that affects 1 factor. Then it can be said that the variant that affects 1 factor is the extraction value of 0.859 , which is Lifestyle. 
Table 4.40

Total Variance Explained

Total Variance Explained

\begin{tabular}{|c|c|c|c|c|c|c|c|c|}
\hline \multirow[b]{2}{*}{ Comp } & \multicolumn{5}{|c|}{ Initial Eigenvalues Sums of Squared } & \multicolumn{3}{|c|}{ Sums of Squared $\mathrm{L}$} \\
\hline & Total & f Varianulativ & Total & f Varia & nulativ & Total & f Varia & nulative \\
\hline 1 & ,567 & $\$ 1,853 \$ 1,853$ &, 567 & 1,853 & $\$ 1,853$ & 139 & 57,098 & 57,098 \\
\hline 2 & 085 & 2,059 3,912 & 085 & 2,059 & 7,912 &, 513 & 6,814 & 3,912 \\
\hline 3 & ,763 & $8,481 \beta 2,393$ & & & & & & \\
\hline 4 & 619 & $6,88039,273$ & & & & & & \\
\hline 5 & ,369 & $4,099) 3,372$ & & & & & & \\
\hline 6 & ,249 & $2,770,96,141$ & & & & & & \\
\hline 7 & ,178 & $1,98298,123$ & & & & & & \\
\hline 8 & 092 & $1,017) 9,141$ & & & & & & \\
\hline 9 & 077 & ,859 00,000 & & & & & & \\
\hline
\end{tabular}

Extraction Method: Principal Component Analysis.

Based on the values in table 4.40 , it can be seen that the total eigenvalues value of each variable is as follows, income level 5.567, education level 1.085, need level 0.763 , social culture 0.619 , price 0.369 , fashion / design 0.249 , lifestyle 0.178 , interest in buying 0.092 , consumer environment 0.077 . From the values described in table 4.40 there is the highest value is the level of income, then the level of income is the most dominant variable in influencing the $\mathrm{Y}$ variable and there are 2 factor groups in this study.

Figure 4.2

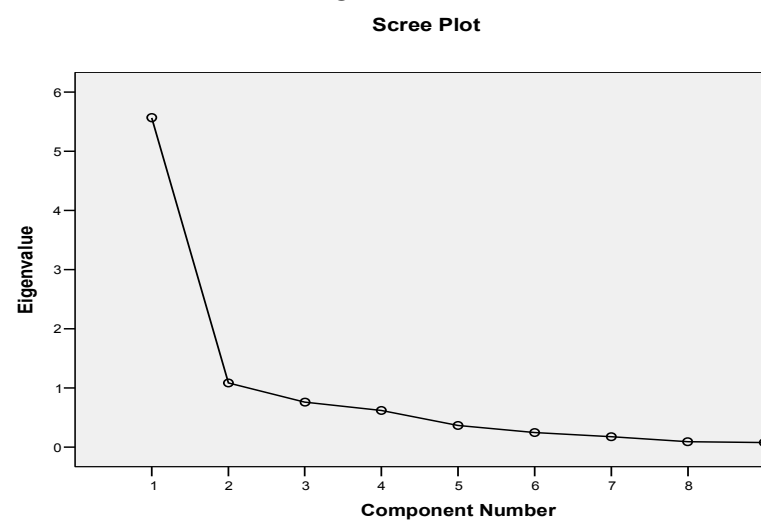

Source : From data processing researcher (2017)

Figure 4.2 is a picture of a scree plot, where picture 4.2 explains the highest value of eigenvalues contained in table 4.42, there is a variable with the highest value is the level of income with eigenvalues 5.567 and the value of other variables needs with eigenvalues 0.763 , social culture with eigenvalues 0.619 , price with eigenvalues 0.369 , mode / design with eigenvalues 0.249 , lifestyle with eigenvalues 0.178 , buying interest with eigenvalues 0.092 , consumer environment with eigenvalues 0.077

Table 4.42

Table 4.42

Rotated Component Matrix

\begin{tabular}{|l|l|l|}
\hline & Initial & Exaction \\
\hline INCOME LEVEL &, 812 &, 242 \\
EDUCATION LEVEL &, 743 &, 331 \\
NEED LEVEL &, 007 &, 855 \\
SOCIO-CULTURAL &, 345 &, 687 \\
PRICE &, 895 &, 190 \\
DESIGN &, 859 &, 247 \\
LIFESTYLE &, 907 &, 193 \\
INTEREST IN BUYING &, 850 &, 087 \\
CONSUMER ENVIRONTMENT &, 851 &, 001 \\
\hline
\end{tabular}

Extraction Method : Principal Component Analysis

Rotation Method : Varimax with Kaiser Normalization

Rotation coverged in 3 iterations

Source : From data processing researcher (2017) 
Based on table 4.42, it is the Rotated Component Matrix ${ }^{a}$ table where there are 2 groups of variables in which there are several variables in each group. The variable group 1 includes the variable income level, education level, price, fashion / design, lifestyle, buying interest, consumer environment. While the variable group 2 includes the Requirement and Socio-Cultural Level variables.

Next will be explained by drawing the Component Plot in Rotated Space where the image will explain the group of variables, namely group variables 1 and group variables 2 .

\section{Component Plot in Rotated Space}

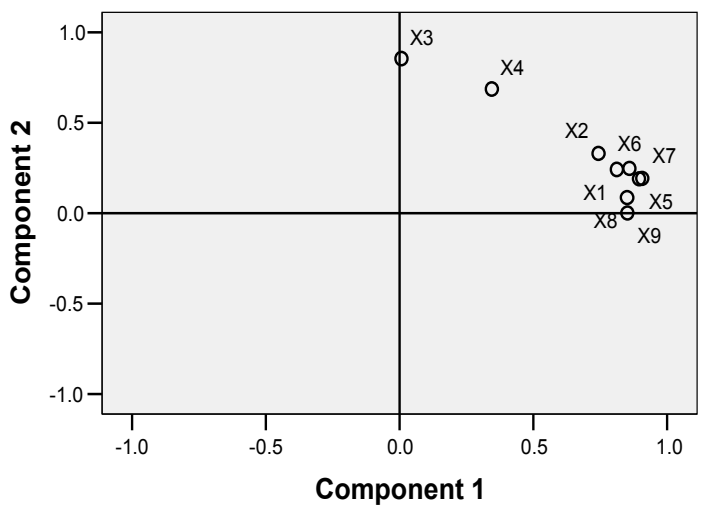

Figure 4.3

Source : From data processing researcher (2017)

It is known from Table 4.41 Component Matrix a and table 4.42 Rotated Component Matrix ${ }^{\mathrm{a}}$ it can be seen that the factors that affect Purchasing Power are divided into 2 groups of variables or 2 factors. Based on figure 4.3, the Component Plot in Rotated Space explains that group 1 includes the variable Income Level, Education Level, Price, Mode / Design, Lifestyle, Buying Interest, Consumer Environment. While group 2 includes the Level of Need and Social Culture variables.

\section{CONCLUTION}

Based on the research that has been done with an explanation of the results of the research shown in the previous chapter, some conclusions can be drawn as follows:

From the results of the factor analysis conducted in this study, it is known that factors that can affect the purchasing power of GW bag consumers in Probolinggo are income level, education level, level of need, social culture, price, fashion / design, lifestyle, buying interest and environment consumer.

In this study the dominant factor that influences the purchasing power of consumers of GW bags in probolinggo is the level of income.

\section{References}

Arai, T., Aiyama, Y., Sugi, M. \& Ota, J. (2001), "Holonic Assembly System with Plug and Produce”, Computers in Industry 46, Elsevier, 289-299.

Bell, G.A., Cooper, M.A., Kennedy, M. \& Warwick, J. (2000), “The Development of the Holon Planning and Costing Framework for Higher Education Management”, Technical Report, SBU-CISM-11-00, South Bank University, 103 Borough Road, London, SE1 0AA.

Bongaerts, L. (1998), "Integration of Scheduling and Control in Holonic Manufacturing Systems", PhD Thesis, PMA Division, K.U.Leuven.

Deen, S.M. (1993), “Cooperation Issues in Holonic Manufacturing Systems”, Proceedings of DIISM'93 Conference, 410-412.

Techawiboonwong, A., Yenradeea, P. \& Das, S. (2006). A Master Scheduling Model with Skilled and Unskilled Temporary Workers", Production Economics 103, Elsevier, 798-809.

Valckenaers, P., Van Brussel, H., Bongaerts, L. \& Wyns, J. (1997), "Holonic Manufacturing Systems", Integrated Computer Aided Engineering 4(3), 191-201.

Van Brussel, H., Wyns, J., Valckenaers, P., Bongaerts, L. \& Peters, P. (1998), "Reference Architecture for Holonic Manufacturing Systems: PROSA”, Computers in Industry 37(3), 255-274. 